\title{
DETERMINATION OF DOSE PROFILE DATA WITH FILM DOSIMETRY
}

\author{
Tuncay C. Gokce ${ }^{1}$, Sitki Aytac ${ }^{2}$, Tumay Gokce ${ }^{3}$ \\ ${ }^{1}$ Department of Computer Engineering, Izmir Instute of Technology, Izmir, Turkey \\ ${ }^{2}$ Department of Computer Engineering, Izmir Instute of Technology, Izmir, Turkey \\ ${ }^{3}$ Department of Radiation Oncologv, Atatïrk State Hospital, Izmir, Turkey
}

\begin{abstract}
Almost all external radiotherapy planning systems use dose profile data. There are various methods to measure these profiles. Direct measurements with semiconductor detectors are widely used. But this method takes lots of time especially at lineer accelerators. We developed a simple method for this purpose. Dose profiles are measured with using radiographic films and verification films. Suitable modifications are done with derived sensitometric curve. Results are compared with original profiles. For the Co60, this method is found as an alternative to other methods with acceptable accuracy $(\% \pm 2)$.

Keywords - Profile, planning, film, OAR, radiotherapy
\end{abstract}

\section{INTRODUCTION}

All radiotherapy planning systems use dose profile data. There are various methods to measure dose profiles. These methods are using an ionization chamber detector in water phantom, thermoluniscent dosimeters, radiographic or radiochromic films, light detectors and semiconductor detectors [1].

All of these methods have some advantages and disadvantages. In this work we use ordinary radiographic films and special port films to measure dose profiles (and OAR values).

\section{METhODOLOGY}

Dose profiles (or OAR values) depend on a scanned dose measurements perpendicular to the central axis, across a beam. Dose profiles are normally made at several depths of interest (least three levels). Fig. 1, shows a dose profile [2].

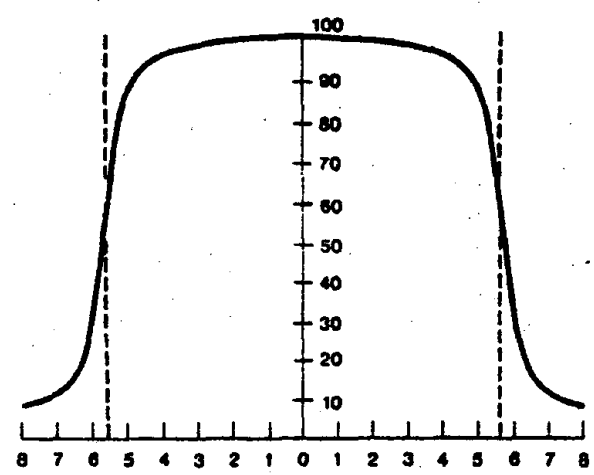

Figure 1: Measured depth dose profile showing variation of dose across the field. SSD $=80 \mathrm{~cm}$, depth $=20 \mathrm{~cm}$. Dotted line indicates geometric field boundary.
OAR is off-axis ratio that indicates variation in dose with several distances from the central axis at same depth. OAR's can be directly measured by several methods or extracted from dose profile graphics [3]. These measurements have done with a film dosimetry system.

Two film categories are used.

1) Kodak radiography film.

2) Kodak radiation therapy verification film.

Measurements are done three or more depths of solid phantom material.

These depths can be 5,10,15 centimeters. First of all, film places tightly to phantom and perpendicular to the central axis of the beam.

The film edge is carefully aligned with the phantom plate surface and air pockets between the film surface and the surrounding jacket.

Then the films are scanned with high resolution transparent scanner device. The scanner that was used for scanning the films is Umax Mirage II model. Optical densities are measured in equal ratio distances from the central axis. Optical densities are correlated by using a depth dependent sensitometric curve. Raw data obtained from the film is shown in the fig. 2 .

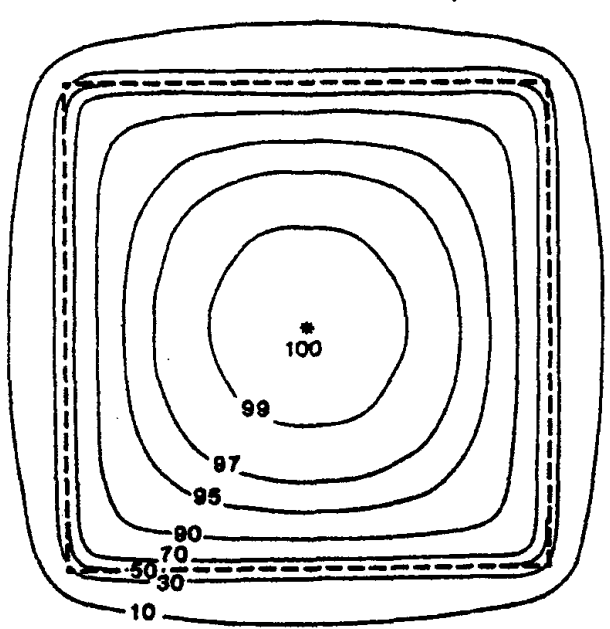

Figure 2: Cross-sectional isodose distrubition in a plane perpendicular to the central axis of the beam. Isodose values are normalized to $100 \%$ at the center of the field. 
A plot of net optical density as a function of radiation exposure or dose is termed the sensitometric curves are derived from known central axis depth dose data for a reference field size $(10 \times 10 \mathrm{~cm})$.

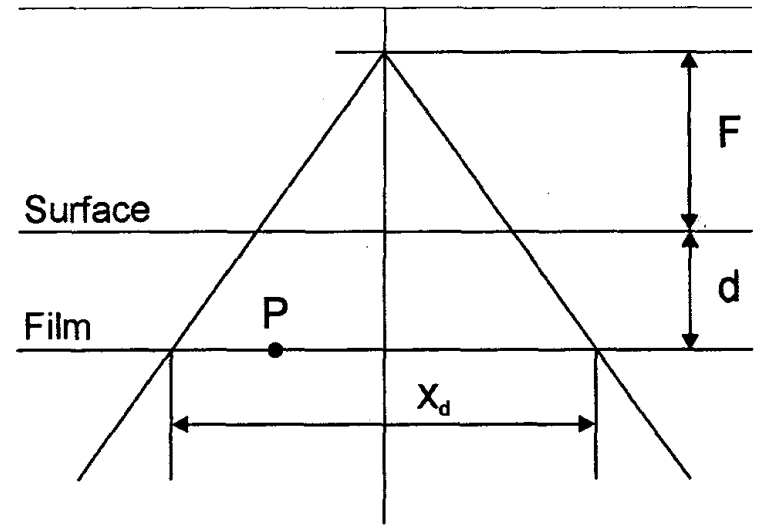

Figure 3: Film dosimetry setup.

The measurement setup is shown in the figure 3. And parameter explanations are defined as bellow:

F: $\quad$ Source to isocenter (or any reference point) distance:

d: Depth of interested point $P$

P: Interested point.

Xd: Projected field size at $d$ depth.

Yd: Lateral distance from central axis.

At each depth and each field sizes, Yd, OCR's are measured at the same series of beam width ratios $2 \mathrm{Yd} / \mathrm{Xd}$.

The smallest value is $D, D$ that represents the beam central axis. A value of $I, O$ represents the beam edge and a value greater than I, O represents past the field edge. Sensitometric curve is more linear for a port film.

Isodose charts are drawn with the profile data which derivation of explained above, compared with original isodose chart which given by the manufacturer isodose charts.

\section{RESULTS}

In this work films are taken three depths, maximum 50 field width ratios and 10 field sizes (from $6 \times 6$ to $30 \times 30 \mathrm{~cm}$ ) for Cobalt-60 teletherapy units (Theratron 780-c).

Optical densities are correlated with derived sensitometric curves. And thereafter isodose charts are drawn for some field sizes with using these data and a computer program, which use this type of data.
For the cobalt-60 source, film has been found to measure profiles with acceptable accuracy $( \pm \% 2)$.

\section{CONCLUSION}

A radiological film consists of a transparent film base (cellulose acetate or polyester resin) coated with an emulsion containing very small crystals of silver bromide. When the film is exposed to ionizing radiation the crystals are affected. When the film is developed, the crystals are reduced to metallic silver. The film is then fixed. The unaffected silver bromide is removed from the fixer. The metallic silver, which is not affected causes darkening of the film. Thus the degree (optical density) of the film depends on the radiation energy absorbed.[1,4]

But optical density is not change linearly with radiation dose. It varies one kind film to another. Therefore a sensitometric curve must be drawn.[2]

Second important procedure is determining the net optical density, which is obtained by subtracting the reading for the base fog from the measured optical density. Calibration of scanner, fixing apparatus and chemical quality, using of same kind films are important issues also, to decrease errors.

\section{REFERENCES}

[1] Faiz M. Khan, Ph. D. "Treatment Planning Isodose Distributions", The Physics of Radiation Therapy 2nd ed. Williams and Wilkins, (1994), p45.

[2] Gunderson, MD, MS and Joel E. Tepper, MD Clinical Radiation Oncology Churchill Livingstone, (2000)

[3] C.Chui. "Off center ratios for three dimensional dose calculations," Med.Phys 13, (1.986), p409.

[4] J.E. Shaw, "4. Conventional Algorithms For 2DDOSE Calculations", Teaching Course in Physics for Clinical Radiotherapy, Leuven, Belgium 1-5 September,"

(1996), p103. 